\title{
An Application of DEMATEL Method in the Analysis of Influence Factors of Postgraduate Innovation Capacity
}

\author{
Junguo Wang \\ Guangdong Vocational College of Commerce and Industry \\ Guangdong. China \\ 13836106410@163.com
}

\author{
Panpan Li* \\ School of Management \\ Harbin Engineering University \\ Harbin. China \\ 906572225@qq.com
}

\author{
Demei Sun \\ School of Management \\ Harbin Engineering University \\ Harbin. China \\ Sundemei2005@163.com
}

\begin{abstract}
The evaluation of postgraduate innovation capacity is an important assessment of the education work. On the basis of the research results of the existing postgraduate innovation capacity, this article includes a new innovative management thinking-“Government-Enterprises-University-Academy-User”, the evaluation index system of postgraduate innovation capacity is constructed from four aspects: the innovative subject, the influence of the tutor, the research practice and the innovation environment, and uses the DEMATEL method to analyze the influence factors of postgraduate innovation capacity. The result indicated that cooperative communication, academic atmosphere and academic guidance are the key factors that influence the postgraduate innovation capacity, and provide proposal for create a good environment for scientific research and innovation, increase the chance of cooperation and communication, improve the consciousness and motivation of innovation, and hope that can be provide reference for postgraduate tutor, universities and education departments.
\end{abstract}

Keywords-Postgraduate; Innovation Capacity; DEMATEL Method

\section{INTRODUCTION}

In the book of " $\mathrm{Xi}$ jinping roundup on scientific and technological innovation" point out that innovation is a strategic support for improving the productive forces and the overall national strength of China. It must be placed at the core position of China's global development. At the same time, as the cradle of cultivating innovative talents in universities, postgraduate as the main object of innovation culture, the innovative capacity of postgraduate in universities is one of the indicators to measure the level of talent cultivation in universities. From the perspective of Chinese academic circles,

1. The research project of the education teaching reform in Heilongjiang province (JGXM_HLJ 2015018)

2. Higher education institute of higher education in Heilongjiang province to study the 13th five-year plan project (16G031)

3. China's 12th five-year plan of education science in Heilongjiang province (GJB1215022) the research on the influence factors of postgraduate innovation capacity is abundant, for example, in the search for "postgraduate innovation capacity" as the key word in "CNKI", there are 1668 papers just journal, but most of them are theoretical study, it only points out the influence factors of the postgraduate innovation capacity, there isn't in-depth analysis of the relationship between them. Therefore, this paper basis on the existing research results and uses the method of DEMATEL to tease out the influence factors of postgraduate innovation capability. Determine the key factors and analyze the influence relationship between factors, based on the analysis results; the paper puts forward some suggestions to improve the innovation capability of postgraduate.

\section{THE IMPLICATION AND INFLUENCE FACTORS OF POSTGRADUATE INNOVATION CAPACITY}

\section{A. The implication of postgraduate innovation capacity}

In the context of the knowledge economy era and the strengthening of international competitiveness, national development and national prosperity revival are closely related to the improvement of the country's overall innovation ability. Postgraduate who as a driving force for national innovation and future technological progress, the level of innovation capability of postgraduate directly influences national development and social progress. Therefore, to study the postgraduate innovation capability, first of all, we should have an in-depth understanding of the concept of "postgraduate innovation capability". At present, domestic scholars have different views on this concept: Yang shuzi(2001)put forward to define postgraduate innovation capability as the ability to ask questions and solve problems, and to emphasize the ability of independent thinking ${ }^{[1]}$;Zhu xiaojun(2007)believed that the postgraduate innovation capability is limited to the level of knowledge innovation, include the ability to recognize, understand and grasp the results of specific professional 
knowledge, the ability to apply and bring forward new insights, and to identify the individual and social value of knowledge innovation $^{[2]}$;Ye haizhi(2008)believed that the postgraduate innovation capability is combination of intelligence and nonintellectual factors, mainly composed of knowledge structure, innovation consciousness, innovation thinking and innovation practice $^{[3]}$;Chen xinzhong(2010)believed that it is the ability of postgraduate use knowledge and external conditions to recognize, analyze, propose and solve problems ${ }^{[4]}$.In conclusion, This paper considers that postgraduate innovation capability is that as the main body of innovation who have the awareness, thought and ability, in scientific research and practice activities, dynamic analysis and found some problems, and using the scientific method to solve the problem, to transform and explore the objective world, and generate novel, unique ideas, views and methods of social or personal significance.

\section{B. The analysis on the influence factors of postgraduate innovation capability}

Essentially speaking, the comprehensive evaluation index system of postgraduate innovation capability of the various indicators and the influence factors of postgraduate innovation capability are equivalent. The current evaluation index system generally includes innovation basic knowledge, innovative thinking, innovation ability, scientific research environment, etc. Such as: Chen zhenbin(2007) proposed to construct the evaluation index system of postgraduate innovation capability include innovative spirit, innovative thinking, physical and mental quality, scientific research environment, scientific research practice and research results ${ }^{[5]}$;Jin li(2013) proposed to construct evaluation index system of engineering postgraduate innovation capability is based on scientific research innovation, academic situation, innovative thinking, innovation capability, scientific research quality and scientific research environment ${ }^{[6]}$;On the basis of the research results of the existing postgraduate innovation capacity, this article includes a new innovative management thinking-“GovernmentEnterprises-University-Academy-User”, which requires the government to play the guide role, enterprises and industries play the lead role, universities play the main role and research institutions play the collaborative role, while the target users give play to the role of market orientation and feedback ${ }^{[7]}$. The integrated innovation system of "Government-EnterprisesUniversity-Academy-User "puts forward new requirements for the overall innovation level of universities. Song weiming(2012) pointed out the core of the deepening of the integration of "Government-Enterprises-University-AcademyUser" was innovate talents, it should integrate the innovation resources of the campus, built a group of high-quality innovative talents, and foster an innovative team that integrates research and teaching across disciplines and boundaries ${ }^{[8]} ; \mathrm{Li}$ haibin(2010) believed that the level of postgraduate innovation capability depend on the level of the tutor, the ability of independent innovation in universities, the cultivation of innovative talents and the effectiveness of the cooperation of "Government-Enterprises-University-Academy-User " are directly related to the innovation quality and ability of the tutor $^{[9]}$;Zeng hongyuan(2011) considered that the postgraduate research practice was the key way to cultivate and improve the postgraduate innovation capability, "Government-Enterprises-
University-Academy-User" required postgraduate to face the forefront of production and research, actively participate in innovation practice, and improve innovation ability in practice ${ }^{[10]}$;Zhang xiekui(2016)put forward want to achieve the win-win cooperation between "Government-EnterprisesUniversity-Academy-User", it need to provide high quality hardware and innovation environment for innovative talents ${ }^{[11]}$.

To sum up, follow the principles of science, comprehensiveness and operability, this paper combines the innovation ability evaluation index system by domestic scholars and the innovation management thinking of "Government-Enterprises-University-Academy-User", and reintegration and build the influence factor system of postgraduate innovation capability. As shown in table 1 .

As is shown in chart 1 , the four principal factors and eleven sub-factors aren't completely independent, such as the innovation consciousness of the innovation subject (university graduate) will influence the scope, depth and effect of participating in scientific research practice, and it can also promote the diversified development of scientific research practice; the academic level and guiding ability of the tutor influence the innovation consciousness and innovation ability of the innovation subject, meanwhile, if the innovation subject has a high degree of innovation awareness, it also demands and challenges the comprehensive level of the tutor; the better innovation environment provides the external condition for teachers and postgraduates to carry out research practice, at the same time, if the vast majority of teachers and postgraduates in a university have high innovation ability which is conducive to the formation of the good innovation environment. Thus, the sub-factors are not completely independent.

TABLE I. SMART CITY INFORMATION SECURITY EVALUATION INDEX SYSTEM

\begin{tabular}{|c|c|c|c|}
\hline Destination Layer & Principal Factor & $\begin{array}{l}\text { Sub-factor } \\
\text { 1.1Innovation consciousness }\end{array}$ & $\begin{array}{l}\text { Encoding } \\
\text { F1 }\end{array}$ \\
\hline \multirow{10}{*}{ 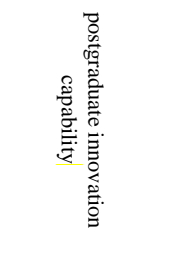 } & 1.Innovation subject & 1.2Innovation motivation & F2 \\
\hline & & 1.3 Volitional quality & F3 \\
\hline & & 2.1 Academic moral & F4 \\
\hline & 2.Tour influence & 2.2 Academic level & F5 \\
\hline & & 2.3 Academic guidance & F6 \\
\hline & & 3.1 Theoretical research & F7 \\
\hline & 3. Research practıce & 3.2 Practical research & F8 \\
\hline & & 4.1Academic atmosphere & F9 \\
\hline & 4.Innovation environment & 4.2 Research condition & F10 \\
\hline & & 4.3Cooperation and exchange & F11 \\
\hline
\end{tabular}

III. ANALYSIS ON THE INFLUENCE FACTORS OF POSTGRADUATE INNOVATION CAPABILITY BASED ON DEMATEL

The DEMATEL method proposed by American scholars is a method of system factor analysis using graph theory and matrix, through the analysis of the logical relations among the elements in the system, based on this, the direct influence matrix is constructed to calculate the relationship between factors, and get the center degree and reason degree ${ }^{[12]}$. This method not only quantitatively analyze the influence factors of the system, but also through the schematic diagram show the importance of various influence factors to help the feasibility measures are put forward. This paper combines DEMATEL with the innovation management thinking of "GovernmentEnterprises-University-Academy-User"which is an exploratory 
innovation. The process of detailed study for the 11 influence factors is carried out by DEMATEL, as follows:

\section{A. Determine the system's influence factors}

In the above analysis, 11 influence factors of postgraduate innovation capability have been determined, Namely, F1 (innovation consciousness), F2 (innovation motivation), F3 (volitional quality), F4 (academic moral), F5 (academic level), F6 (academic guidance), F7 (theoretical research), F8 (practice research), F9 (academic atmosphere), F10 (scientific condition), and F11 (cooperation and exchange).

\section{B. Determine the direct influence matrix $X$}

In this survey, we surveyed tours and postgraduates in more than 10 universities, issued 34 questionnaires, withdraw 34 copies, and these are effective questionnaires. The direct influence degree of the influence factors was analyzed with $0-3$ scale. Among them, 0 represents no influence among the corresponding factors, and 1 represents the weakest direct influence among the corresponding factors and 3 represents the most direct influence among the corresponding factors. Through the analysis of the effective questionnaire and the highest frequency score as the direct influence factors of postgraduate innovation capability, and finally get the direct influence matrix $X$ of the influence factors of the postgraduate innovation capability. The results are shown in table 2 .
TABLE II. DIRECT INFLUENCE MATRIX X

\begin{tabular}{ccccccccccc}
\hline F1 & F2 & F3 & F4 & F5 & F6 & F7 & F8 & F9 & F10 & F11 \\
0 & 3 & 3 & 0 & 0 & 0 & 1 & 1 & 1 & 0 & 0 \\
& & & & & & & & & & \\
3 & 0 & 3 & 0 & 0 & 0 & 1 & 1 & 1 & 0 & 0 \\
1 & 1 & 0 & 0 & 0 & 0 & 1 & 1 & 0 & 0 & 0 \\
0 & 1 & 0 & 0 & 0 & 1 & 0 & 0 & 1 & 0 & 0 \\
1 & 0 & 0 & 2 & 0 & 2 & 0 & 0 & 0 & 1 & 0 \\
1 & 1 & 1 & 0 & 0 & 0 & 2 & 2 & 1 & 0 & 0 \\
1 & 0 & 1 & 0 & 0 & 0 & 0 & 1 & 1 & 1 & 0 \\
1 & 0 & 1 & 0 & 0 & 0 & 1 & 0 & 1 & 1 & 0 \\
2 & 2 & 0 & 0 & 1 & 1 & 1 & 1 & 0 & 0 & 0 \\
0 & 0 & 0 & 0 & 1 & 0 & 3 & 3 & 0 & 0 & 0 \\
1 & 1 & 0 & 0 & 1 & 1 & 2 & 2 & 2 & 1 & 0 \\
\hline
\end{tabular}

C. Determine the normalized influence matrix $G$

The normalized direct impact matrix $G$ was determined by use formula (1).

$$
\mathrm{G}=\frac{1}{\max _{1 \leq \mathrm{i} \leq \mathrm{n}} \sum_{\mathrm{j}=1}^{\mathrm{n}} \mathrm{x}_{\mathrm{ij}}} X
$$

Among them, $\mathrm{X}$ is the direct influence matrix, and $x_{i j}$ is the direct influence of $F_{i}$ on $F_{j}$. Using this formula to calculate the normalized direct influence matrix $G$. The results are shown in table 3 .

TABLE III. NORMALIZED INFLUENCE MATRIX G

\begin{tabular}{ccccccccccc}
\hline F1 & F2 & F3 & F4 & F5 & F6 & F7 & F8 & F9 & F10 & F11 \\
& 0.273 & 0.273 & & & & 0.091 & 0.091 & 0.091 & & \\
0.273 & & 0.273 & & & & 0.091 & 0.091 & 0.091 & & \\
0.091 & 0.091 & & & & & 0.091 & 0.091 & & & \\
& 0.091 & & & & 0.091 & & & 0.091 & & \\
0.091 & & & 0.182 & & 0.182 & & & & 0.091 & \\
0.091 & 0.091 & 0.091 & & & & 0.182 & 0.182 & 0.091 & & \\
0.091 & & 0.091 & & & & & 0.091 & 0.091 & 0.091 & \\
0.091 & & 0.091 & & & & 0.091 & & 0.091 & 0.091 & \\
0.182 & 0.182 & & & 0.091 & 0.091 & 0.091 & 0.091 & & & \\
& & & & 0.091 & & 0.273 & 0.273 & & & \\
0.091 & 0.091 & & & 0.091 & 0.091 & 0.182 & 0.182 & 0.182 & 0.091 & \\
\hline
\end{tabular}

\section{Determine the comprehensive influence matrix $T$}

The comprehensive influence matrix $\mathrm{T}$ was determined by use formula (2).

$$
\mathrm{T}=\mathrm{G}(I-G)^{-1}=\left(t_{i j}\right)
$$

Among them, $I$ is the unit matrix, and $t_{i j}$ represents the influence of $F_{i}$ on $F_{j}$. According to formula (2) and table 3, the comprehensive influence matrix $\mathrm{T}$ can be calculated. The results are shown in table 4.

\section{E. Determine the influence degree}

The influence degree is the sum of the various elements in the matrix $\mathrm{T}$, which represents the comprehensive influence value of the corresponding factors on all other factors; The influenced degree is the sum of the column elements in the matrix $\mathrm{T}$, and the corresponding factors representing each column are affected by the comprehensive influence of all other factors. The calculation method is formula (3) and formula (4). The results are shown in table 5.

TABLE IV. COMPREHENSIVE INFLUENCE MATRIX T

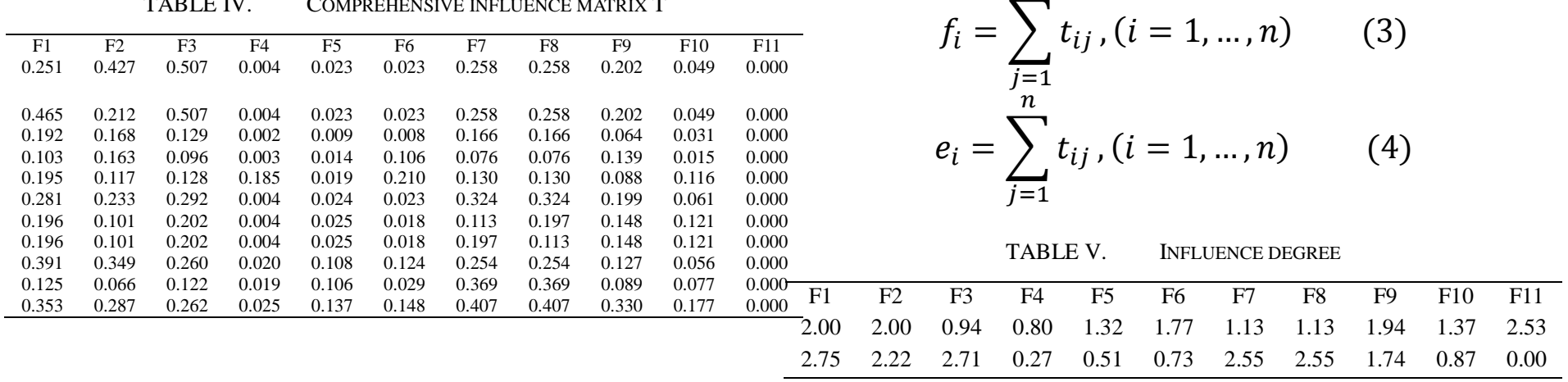




\section{F. Determine the center degree and reason degree}

The center degree represents a certain factor in this evaluation index system location, function size; the reason degree represents the degree of influence of a certain factor on other factors. When reason degree is greater than zero, on behalf of the factor has great influence to the other factors, which is the cause factor, whereas when the reason is less than zero, on behalf of the other factors has a larger effect on the factor, which is the result factor. Calculated by formula (5) and (6). The results are shown in table 6.

$$
\begin{aligned}
& m_{i}=f_{i}+e_{i},(i=1, \ldots, n) \\
& n_{i}=f_{i}+e_{i},(i=1, \ldots, n)
\end{aligned}
$$

TABLE VI. CENTER DEGREE AND REASON DEGREE

\begin{tabular}{ccccccccccc}
\hline F1 & F2 & F3 & F4 & F5 & F6 & F7 & F8 & F9 & F10 & F11 \\
4.75 & 4.23 & 3.64 & 1.07 & 1.83 & 2.50 & 3.68 & 3.68 & 3.68 & 2.24 & 2.53 \\
-0.75 & -0.22 & -1.77 & 0.52 & 0.81 & 1.04 & -1.43 & -1.43 & 0.21 & 0.50 & 2.53 \\
\hline
\end{tabular}

\section{G. Map the distribution of important degree and results} analysis

The important distribution map is based on table 6, and the center degree was regarded as the horizontal coordinate, and the reason degree was regarded as the ordinate plot. Shown as in Fig. 1. In this figure, the reason degree is bounded by zero and when it is greater than zero, that is the reason factor: academic moral, academic level, academic guidance, academic atmosphere, research condition, cooperation and exchange (F4, F5, F6, F9, F10, F11); when it is less than zero, that is the result factor: innovation motivation, innovation consciousness, volitional quality, theoretical research, practical research (F1, F2, F3, F7, F8). In the reason degree, the most important reason is the cooperative communication factor, which indicates that this factor has the greatest influence on all other factors, and the result is consistent with the reality, because cooperation and exchange is the important way to improve innovation capability and develop the research field of vision of postgraduate, if the lack of cooperation and exchange opportunity, even if there is a good scientific research conditions, and innovation motivation, which is stagnant of postgraduate innovation capability. The result factor is that other factors have greater influence on it, from table 4, the innovation consciousness of innovation subject are influenced by academic atmosphere, cooperation and exchange and academic guidance, namely, lack of academic atmosphere, opportunities for cooperation and exchange and the academic guidance of the tutor will influence the innovation consciousness of postgraduates. Therefore, in order to improve the innovation consciousness of postgraduates which can start from improving academic atmosphere, enhancing opportunities of cooperative and exchange and improving the level of academic guidance, etc.

In addition, as can be seen from the Fig.1: innovation motivation (F1), innovation motivation (F2), academic atmosphere (F9) and other factors' center degree are big, on behalf of these factors are the key to influence the postgraduate innovation capability, therefore, need to improve the postgraduates' innovation consciousness, innovation motivation and create a good academic atmosphere in order to promote the postgraduate innovation capability.

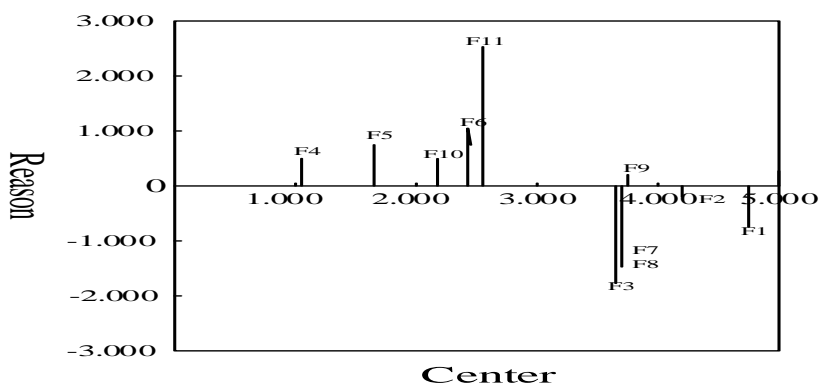

Fig. 1.The reason-center degree

\section{SUGGESTION OF IMPROVE POSTGRADUATE INNOVATION CAPABILITY}

(1) Increasing opportunities for scientific research cooperation and exchange. First, to break through the traditional mode of scientific research practice and encourage postgraduates to get out of the school gate and get into social reality, to discover and solve problems, to study the practical problems that need to be solved in the practice of social production and to put forward constructive methods. Second, should actively create conditions and increase opportunities for cooperation and exchange to enrich the content and form of postgraduates' social practice activities. Third, universities should establish long-term and stable relations and multidirectional cooperation with enterprises, in order to jointly accomplish some scientific research and production tasks. It is possible to establish a university science park, based on the scientific research institutions of the university, and jointly develop a technology park to build a platform for postgraduates to participate in practice and improve their innovation capability.

(2) To improve the innovation consciousness and innovation motivation of postgraduates. First, to improve the mechanism for protecting innovation outcomes. Because information has a reproducible nature, this requires a timely and comprehensive protection of innovative outcomes. Establish innovation protection mechanism to punish the plagiarism and theft by policy and law, in order to eliminate the worries of the owners of the innovation outcomes and make the innovations fully play their value, to avoid the waste of resources and safeguard the interests of the innovation subject. Second, to improve the incentive mechanism for innovation. In the scientific research team, after the members have achieved the innovation results, the team should give a certain amount of 
material incentive and mental stimulation in order to encourage them to further improve their innovation ability.

(3) Create a good environment for scientific research. Through create democratic academic atmosphere, improve the conditions of university and cultivate culture of harmonious trust in order to meet students' needs and desires of resources and information.

(4) High level and quality of tour team. Tour need to improve the innovation capability and academic level, and update the knowledge structure, pass the latest research outcomes to postgraduates. Influence postgraduates with their own personality, scientific research spirit and research style.

\section{REFERENCES}

[1] Yang shuzi. On the quality and creativity of talents ambition capability and related exterior circumstances [J]. Journal of high education, 2001(4):64-67(In Chinese)

[2] Zhu xiaojun. Research on the guidance factors in the cultivation of postgraduate students' innovation ability [J]. Journal of Changsha Railway University, 2007(3):246-248(In Chinese)

[3] Ye haizhi.The innovation ability cultivation strategy of graduate students based on tacit knowledge theory [J], China higher education research, 2008(1):25-26(In Chinese)
[4] Chen xinzhong. Three basic problems of postgraduate innovation ability evaluation [J]. Academic degrees \& graduate education, 2010(1):10-13 (In Chinese)

[5] Chen zhenbin. The grey clustering assessment model of postgraduates' ability on innovation [J]. Journal of liaoning technical university, 2007(3):288-290(In Chinese)

[6] Jin li. Establishment and application of scientific research innovation capability evaluation index system for postgraduates of science and engineering in colleges and universities [J]. Journal of Zhejiang sci-tech university, 2013, 30(3):419-213(In Chinese)

[7] Tuyaqing."Government-Enterprises-University-Academy-User" cooperation education to train graduate students' innovation ability [J]. China electric power education, 2011(26):56-58(In Chinese)

[8] Song weiming. Integration of government and industry: the breakthrough of collaborative innovation of agricultural and forestry universities [J]. Information Security and Communications Privacy, 2012(3): 19-21(In Chinese)

[9] Li haibin. Applying experience of enrollment system in Europe for reference, improving educational level of domestic medical postgraduates [J].Higher education forum, 2010(4):108-110(In Chinese)

[10] Zeng yuanhong. On the cultivation of college students' innovation ability [J]. Forum on Contemporary Education, 2011(6):31-33(In Chinese)

[11] Zhang xiekui. To explore the training of regional economics graduate student' innovation ability [J]. Higher education forum, 2016(1):4-7(In Chinese)

[12] Zhang ling. Analysis of influence factors for teaching quality of higher education based on DEMATE [J]. Journal of Nanjing university of aeronautics \& astronautics, 2009(1):49-52(In Chinese) 